\title{
Prenatal diagnosis of Wolf-Hirschhorn syndrome (4p-) in association with congenital hypospadias and foot deformity Halil Aslan*1, Nilay Karaca ${ }^{2}$, Seher Basaran ${ }^{3}$, Hayri Ermis ${ }^{4}$ and Yavuz Ceylan ${ }^{1}$
}

Address: ${ }^{1}$ Department of Perinatology, SSK Bakirkoy Maternity and Children Hospital, Istanbul, Turkey, ${ }^{2}$ Department of Obstetric and Gynecology, SSK Vakif Gureba Hospital, Istanbul, Turkey, ${ }^{3}$ Department of Genetics (PRETAM), Faculty of Medicine, Istanbul University, Istanbul, Turkey and ${ }^{4}$ Department of Obstetric and Gynecology, Faculty of Medicine, Istanbul University, Istanbul, Turkey

Email: Halil Aslan* - halil34aslan@hotmail.com; Nilay Karaca - nkaraca@yahoo.com; Seher Basaran - basarans@hotmail.com; Hayri Ermis - hermis@superonline.com; Yavuz Ceylan - yceylan@yahoo.com

* Corresponding author

Published: 24 January 2003

BMC Pregnancy and Childbirth 2003, 3:1
Received: 16 October 2002

Accepted: 24 January 2003

This article is available from: http://www.biomedcentral.com/I47/-2393/3/I

(C) 2003 Aslan et al; licensee BioMed Central Ltd. This is an Open Access article: verbatim copying and redistribution of this article are permitted in all media for any purpose, provided this notice is preserved along with the article's original URL.

\begin{abstract}
Background: Wolf-Hirschhorn syndrome is caused by distal deletion of the short arm of chromosome $4(4 \mathrm{p}-)$. We report a case in which intrauterine growth restriction, hypospadias and foot deformity were detected by prenatal ultrasound examination at 29 weeks of gestation.

Case Presentation: A 3 I-year-old gravida 2 partus I woman was referred at 29 weeks' gestation with suspicion of intrauterine growth restriction. Sonographic examination revealed deformity of the right lower limb and undescended testes with an irregular distal penis. A cordocentesis was performed and chromosome analysis revealed a 46,XY,del(4)(pl4) karyotype.
\end{abstract}

Conclusion: The prenatal detection of intrauterine growth restriction, hypospadias and foot deformity should lead doctors to suspect the presence of Wolf-Hirschhorn syndrome.

\section{Background}

Wolf-Hirschhorn syndrome (WHS) is a well-known chromosomal disorder first described by Cooper and Hirschhorn in 1961 [1]. Since the first clinical description, more than 120 cases have been reported [2]. It is attributable to partial loss of material from the short arm of chromosome 4 , with the majority of cases $(87 \%)$ being de novo deletions of preferential paternal origin.

WHS is characterized by intrauterine growth restriction, mental retardation, characteristic facial dysmorphism, microcephaly, ear lobe anomalies and closure defects (cleft lip or palate, coloboma of the eye, and cardiac septal defects) [3].
Prenatal diagnosis of Wolf-Hirschhorn syndrome has been reported in fetuses karyotyped because of routine indications of chromosomal analysis or intrauterine growth restriction with or without associated anomalies [4]. We report a case in which congenital hypospadias and clubfoot was detected prenatally at 29 weeks' gestation in association with intrauterine growth restriction.

\section{Case presentation}

A 31-year-old gravida 2 partus 1 woman was referred at 29 weeks' gestation with suspicion of intrauterine growth restriction. The couple were healthy, nonconsanguineous, with unremarkable medical history. There was no family history of congenital defects. The woman denied cigarette smoking, use of alcohol, illicit drugs or medication, in 


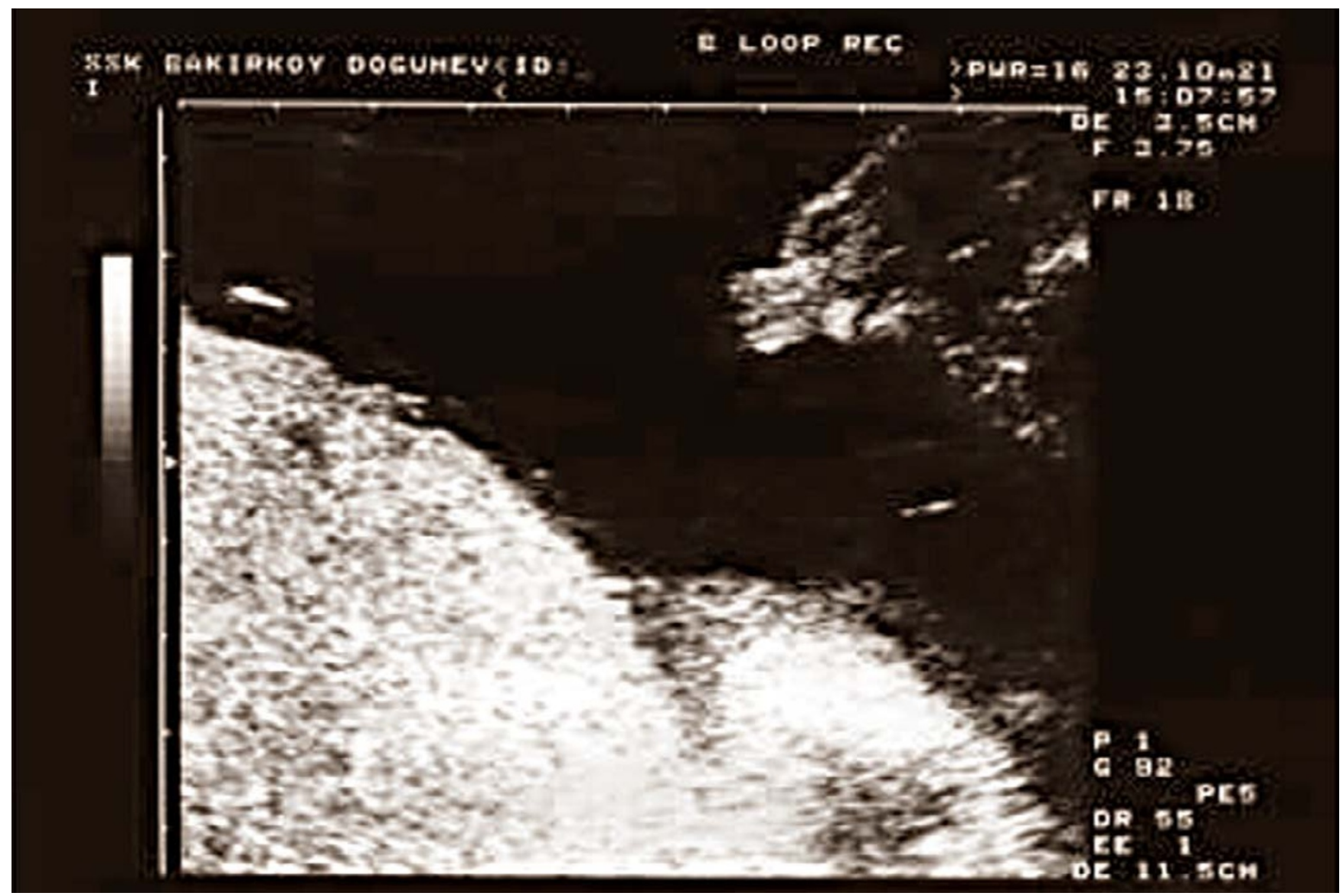

Figure I

Sonographic appearance of fetal genitalia. Note the irregular distal portion of fetal penis and undescended testes.

addition to any intrauterine teratogenic or infectious exposure. Sonographic examination revealed a single live fetus. Fetal biparietal diameter, abdominal circumference and femur length measurements were compatible with 25 weeks' gestation. Amniotic fluid index was $15 \mathrm{~cm}$. Doppler velocimetry of umbilical artery was normal. A $7.3 \mathrm{~cm}$ placental thickness was measured.

Examination of the fetal anatomy revealed a deformity of the right lower limb and undescended testes with an irregular distal penis (Figure 1,2). The parents were informed and a cordocentesis was performed. The karyotype analysis revealed a deletion of the short arm of chromosome 4 , [46,XY,del(4)(p14)] (Figure 4).

A FISH study to confirm the terminal deletion revealed a partial monosomy for 4p 15.2 $\rightarrow$ 4pter (Figure 5). After genetic counseling the family elected for termination of the pregnancy. Labor was induced and the woman delivered a stillborn male fetus weighing $900 \mathrm{~g}$. The baby had prom- inent glabella, short philtrum, low-set ears, hypospadias, undescended testes and calcaneovalgus deformity of the right foot (Figure 3). Except for a large hydropic placenta, no additional anomaly was noted at autopsy. Chromosomal analysis of the woman revealed a normal karyotype $(46, \mathrm{XX})$. Father refused a chromosomal analysis but he has 3 healthy children from his former spouse.

\section{Discussion}

Wolf-Hirschhorn syndrome, caused by partial deletion of the short arm of chromosome 4, is characterised by severe growth restriction and mental defect, microcephaly, 'Greek helmet' facies, and midline fusion defects. The critical zone for development of this disorder is located distal to the Huntington disease-linked G8 (D4S10) marker [5]. Quarrel et al., [6] found that there was de novo deletion or rearrangement of 4p; in cases where the abnormality had arisen on the paternal chromosome. However, a paternal age effect was not observed. Goodship et al., [7] described a 2-year-old who presented with developmental delay and 




Figure 2

Ultrasound scan showing the deformity of foot.

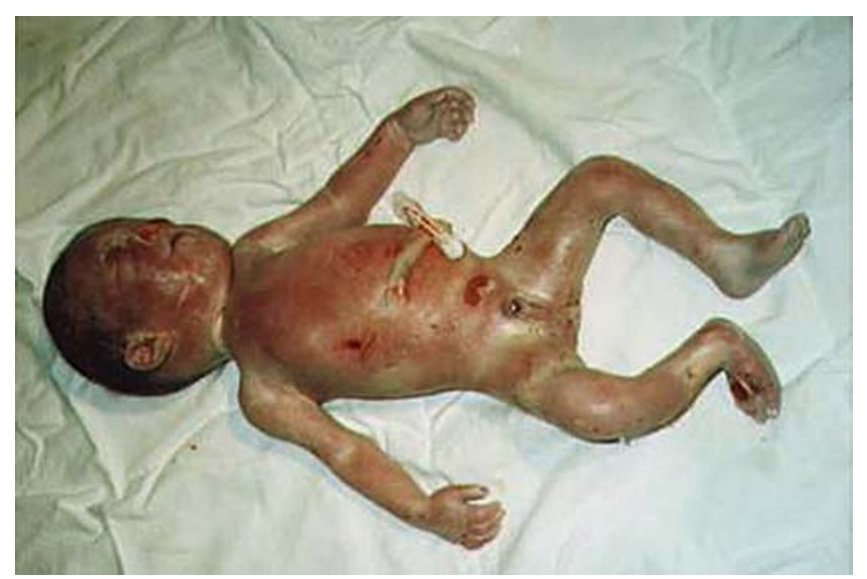

Figure 3

Photograph of the neonate with the Wolf-Hirschhorn syndrome. Note the hypospadias and calcaneovalgus deformity of the foot. subtle dysmorphic features suggesting WHS: hypertelorism, prominent glabella, short philtrum, and carpshaped mouth. Although high-resolution chromosomal analysis was normal in the child and in both parents, molecular analysis indicated that the child had not inherited a maternal allele for probes from $4 \mathrm{p} 16$. Fluorescence in situ hybridization (FISH) in the mother showed a submicroscopic translocation between chromosome 4 and 10 . Chen et al [8] reported on the prenatal diagnosis of two sib female fetuses with a satellited short arm of chromosome 4 and a male fetus with a satellited long arm of chromosome X. The first two fetuses had a cryptic balanced translocation $\mathrm{t}(4 ; 15)(\mathrm{p} 16 ; \mathrm{p} 11.1)$ inherited from a mother carrying a satellited $4 \mathrm{p}$ and having an affected child with the Wolf-Hirschhorn syndrome.

A family was reported with a balanced chromosomal translocation $\mathrm{t}(4 ; 18)(\mathrm{p} 15.32 ; \mathrm{p} 11.21)$ in the father and an unbalanced translocation resulting in partial monosomy 

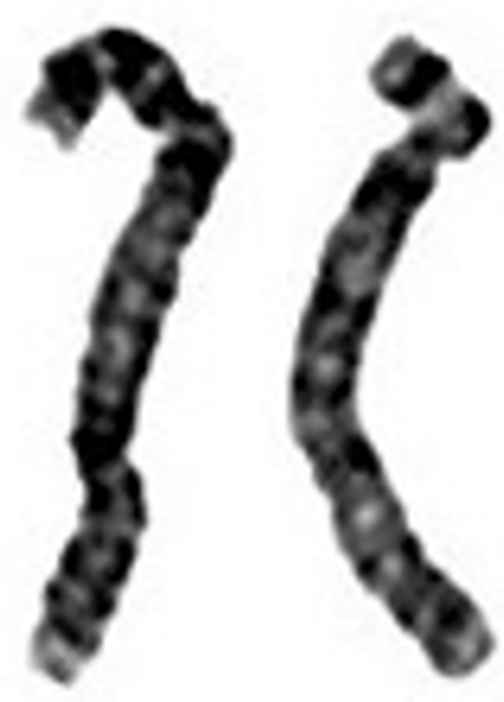

\section{Figure 4}

Note the deletion of short arm of the chromosome 4

4 and partial trisomy 18 in one living boy and a prenatally diagnosed male fetus. Both showed abnormalities consistent with WHS and had in addition aplasia of one umbilical artery [9].

WHS, a relatively common malformation pattern, has been exceptionally diagnosed in fetuses. Prenatal detection of abnormal male genitalia has been accomplished by ultrasonography. Hypospadias is one of the most common anomalies of the male genital tract. During the eighth to tenth week of embryologic development, incomplete fusion of the urethral folds results in an abnormal opening on the ventral surface of the penis. Hypospadias is classified as glandular, penile and scrotal type according to the location of the ectopic urethral meatus. It frequently occurs in isolation, although it can be associated with other anomalies in 8 per cent of cases. There is a recurrence risk of between 4 and 10 per cent. The prenatal diagnosis of hypospadias has been reported in fetuses with a family history [10]. Vinals et al. [11] documented the prenatal detection of congenital hypospadias in a case of Wolf-Hirschhorn syndrome.
Hypospadias is a common feature of several genetic syndromes: XXY and XXXXY and also associated with chromosomal abnormalities such as triploidy, trisomies 13 and 18. Furthermore it can be associated with anomalies of the urinary tract including exstrophy of the bladder, undescended testes, bifid glans, megalourethra and transposition.

Genetic syndromes such as Smith-Lemli-Opitz syndrome, Robinow syndrome, Fraser syndrome, Schprintzen syndrome, short-rib polydactyly syndrome and WHS may be associated with hypospadias [11].

Prenatal diagnosis of cases of monosomy 4p associated with severe IUGR has been reported. Cleft-lip and palate, diaphragmatic hernia, cystic hygroma and heart defect with right ventricular hypoplasia were detected by prenatal ultrasonography. At autopsy, midline fusion defects were observed in fetuses with WHS ranging from minor abnormalities such as scalp defect, hypertelorism, pulmonary isomerism, common mesentery, hypospadias and sacral dimple, to cleft palate, corpus callosum agenesis, ventricular septal defect and diaphragmatic hernia. Hypotrophic placentas with vascular lesions and a large placental chorioangioma have been reported previously [12]. In our case a large otherwise normal placenta was noted.

While a number of prenatally detected anomalies have been reported with WHS, to our knowledge, talipes calcaneovalgus has not been documented before [13].

Calcaneovalgus deformity is characterized by lateral deviation and eversion of the sole of the foot. Congenital club foot encompasses a wide spectrum of severity. It may arise from intrinsic factors, but it is frequently the consequence of restriction of fetal movements. It also commonly found in many syndromes and malformation clusters [14]. A variety of skeletal anomalies were found in patients with WHS, including split hand, clinodactyly, club feet, scoliosis and kyphosis, malformed toes, finger-like appearance of thumb, long slender fingers and delayed bone age [15].

Subtle abnormalities on ultrasound may suggest a chromosomal problem. Standard cytogenetics cannot always demonstrate a microdeletion. High-resolution banding and molecular analysis can help to confirm the diagnosis [16]. The prenatal detection of intrauterine growth restriction, hypospadias and clubfoot should raise the suspicion of WHS. Fetal skeletal and genital abnormalities detected by ultrasound should prompt the search for associated anomalies and karyotyping should be considered in fetuses with intrauterine growth restriction especially with a normal amniotic fluid volume. 


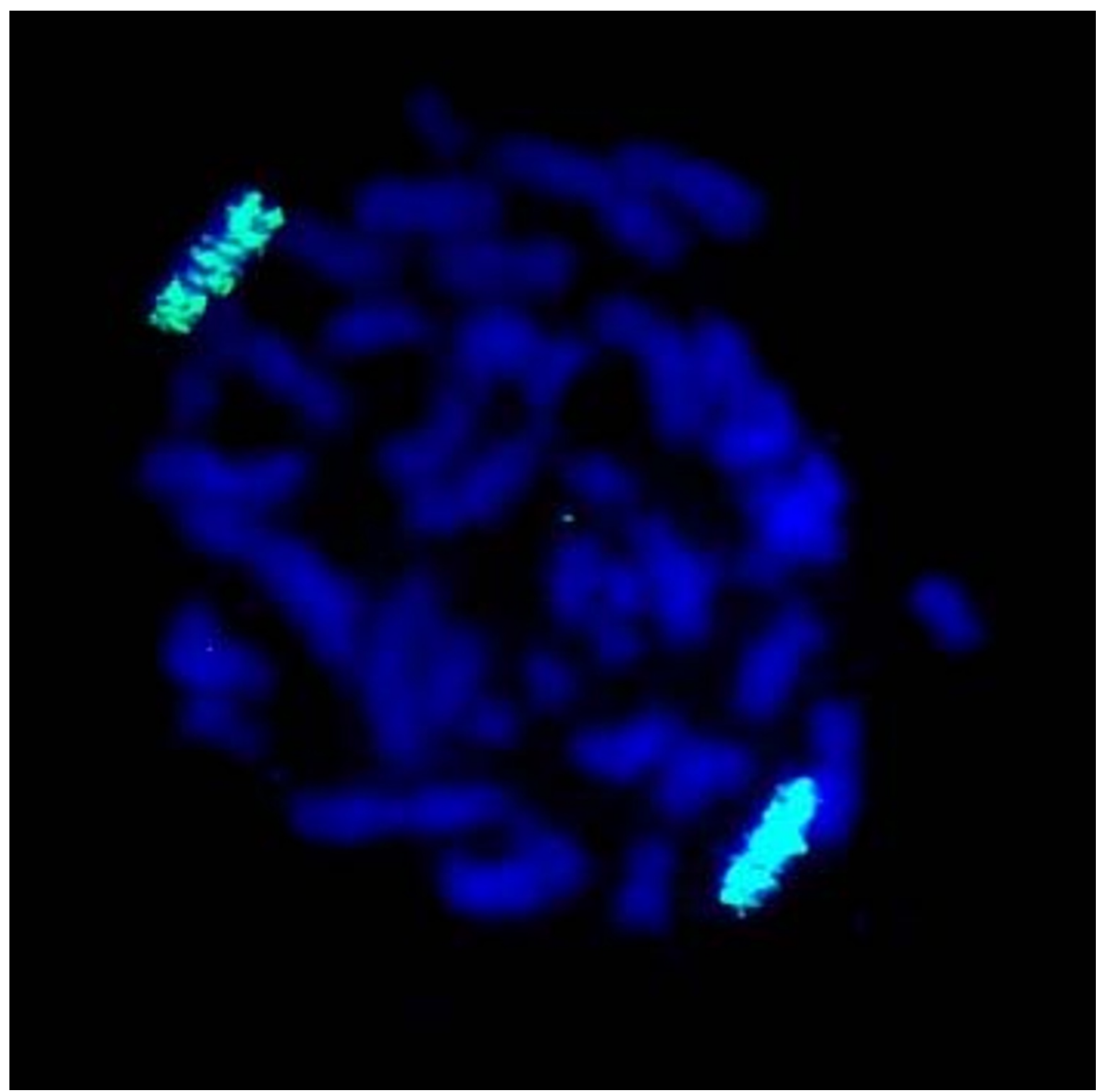

\section{Figure 5}

Fluorescent in situ hybridization. Chromosome 4 is green and the other chromosomes are blue. Neither of the chromosome 4 do not carry an extra piece of DNA.

\section{Competing interests}

None declared.

\section{Acknowledgments}

Written consent was obtained from the patient or their relative for publication of the patient's details.

\section{References}

I. Cooper $\mathrm{H}$ and Hirschhorn $\mathrm{K}$ Apparent deletion of short arms of one chromosome (4 or 5 ) in a child with defects of midline fusion. Hum Chrom Newsl 1961, 4:14-16

2. Verloes A, Schaaps JP, Herens C, Soyeur D, Hustin C and Dodinval P Prenatal diagnosis of cystic hygroma and chorioangioma in the Wolf-Hirschhorn syndrome. Prenat Diagn |99|, I I:| 29- | 32 
3. Lurie IW, Lazjuk GL, Ussova I, Presman EB and Gurevich DB The Wolf-Hirschhorn syndrome. I. Genetics. Clin Genet 1980, 17:375-384

4. Snijders RJ, Sherrod C, Gosden CM and Nicolaides KH Fetal growth retardation associated malformations and chromosomal abnormalities. Am J Obstet Gynecol 1993, 168:547-555

5. Altherr MR, Bengtsson U, Elder FFB, Ledbetter DH, Wasmuth JJ and McDonald ME Molecular confirmation of Wolf-Hirschhorn syndrome with a subtle translocation of chromosome 4. Am J Hum Genet 1991, 49: I 235-1242

6. Quarrel OWJ, Snell RG, Curtis MA, Roberts SH, Harper PS and Shaw $D J$ Paternal origin of the chromosomal deletion resulting in Wolf-Hirschhorn syndrome. J Med Genet I99I, 28:256-259

7. Goodship J, Curtis A, Cross I, Brown J, Emslie J and Wolstenholme J A submicroscopic translocation, $t(4 ; 10)$, responsible for recurrent Wolf-Hirschhorn syndrome identified by allele loss and fluorescent in situ hybridisation. J Med Genet 1992, 29:45 I454

8. Chen CP, Devriendt K, Chern SR, Lee CC, Wang W and Lin SP Prenatal diagnosis of inherited satellited non-acrocentric chromosomes. Prenat Diagn 2000, 20:384-9

9. Kohlschmidt N, Zielinski J, Brude E, Schafer D, Olert J and Hallerman $C$ Prenatal diagnosis of a fetus with a cryptic translocation 4p;18p and Wolf-Hirschhorn syndrome (WHS). Prenat Diagn 2000, 20:152-5

10. Devesa R, Munoz A, Torrents M, Conmas C and Carrera JM Prenatal diagnosis of isolated hypospadias. Prenat Diagn 1998, 18:779788

11. Vinals F, Sepulveda W and Selman E Prenatal detection of congenital hypospadias in the Wolf-Hirschhorn (4p-) syndrome. Prenat Diagn 1994, I4: I 166-II69

12. Tachdjian G, Fondacci C, Tapia S, Huten $Y$, Blot $P$ and Nessmann $C$ The Wolf-Hirschhorn syndrome in fetuses. Clin Genet 1991, 42:28I-287

13. Thompson P Wolf-Hirschhorn syndrome. Review of the literature and three case studies. J Am Podiatr Med Assoc 1998, 88: $192-197$

14. Romero R, Pilu G, Jeanty P and ed Prenatal Diagnosis of Congenital Anomalies, Appleton \& Lange: Norwalk 1988, 65-67

15. Battaglia A, Carey JC, Cederholm P, Viskochil DH, Brothman AR and Galasso $C$ Natural history of Wolf-Hirschhorn: experience with I 5 cases. Pediatrics 1999, 103:830-836

16. De Keersmaecker B, Albert M, Hillion Y and Ville Y Prenatal diagnosis of brain abnormalities in Wolf-Hirschhorn (4p-) syndrome. Prenat Diagn 2002, 22:366-70

\section{Pre-publication history}

The pre-publication history for this paper can be accessed here:

http://www.biomedcentral.com/1471-2393/3/1/prepub
Publish with Bio Med Central and every scientist can read your work free of charge

"BioMed Central will be the most significant development for disseminating the results of biomedical research in our lifetime. "

Sir Paul Nurse, Cancer Research UK

Your research papers will be:

- available free of charge to the entire biomedical community

- peer reviewed and published immediately upon acceptance

- cited in PubMed and archived on PubMed Central

- yours - you keep the copyright
BioMedcentral 